\title{
Determination of Cesium Adsorption Breakthrough Curves Using Carbonized Rice Hull and Beech Sawdust as Adsorbents
}

\author{
Asa Miura \\ Faculty of Education and Regional Studies, University of Fukui, Japan
}

Copyright $\odot 2017$ by authors, all rights reserved. Authors agree that this article remains permanently open access under the terms of the Creative Commons Attribution License 4.0 International License

\begin{abstract}
To determine the adsorption breakthrough curves of carbonized rice hull and beech sawdust, which were selected as candidate natural materials for Cesium (Cs) adsorption in our previous study, fixed-bed adsorption experiments were conducted. These experiments were performed using a glass column with a continuous flow system and a variable packed-bed height of the above materials. For carbonized rice hull, the breakthrough point appeared relatively early, although a long adsorption time was required to reach the end point. In addition, for beech sawdust, the maximum Cs concentration at the column outlet was approximately 1.2 times that at the inlet. Regarding the Cs mass balance in the packed-bed layer, the amount of Cs adsorbed per unit weight of adsorbent was greater for carbonized rice hull than for beech sawdust. Furthermore, the adsorption ratio in the packed-bed was higher for beech sawdust than for carbonized rice hull. However, following estimation of the length of the adsorption zone formed in the packed bed using the model formula commonly employed in the design of the fixed-bed adsorption apparatus, it was not possible to calculate the real length of the adsorption zone.
\end{abstract}

Keywords Cesium, Carbonized Rice Hull, Beech Sawdust, Fixed-bed Layer, Breakthrough Curve

\section{Introduction}

The March 2011 release of radioactive materials from the Fukushima Daiichi Nuclear Power Plant as a result of the Great East Japan Earthquake (also known as the 2011 Tōhoku earthquake) caused widespread damage to the surrounding environment. Following the accident, many countermeasures were taken immediately to minimize the contamination of residential areas within and beyond the Fukushima prefecture.

For example, at the power plant and its surroundings, methods employing zeolites [1] or insoluble synthetic ferrocyanide fibers [2] were employed for the decontamination of high concentrations of radioactive Cesium (Cs). In addition, the use of thiourea-containing sulfuric acid solutions [3], improved wet classification and used of geomaterials [4], and the use of photosynthetic bacteria [5-6] have been being investigated as potential decontamination methods for the treatment of radioactive Cs-contaminated soil.

One of the main concerns regarding the release of radioactive Cs is that it can easily diffuse into wider areas, such as forests, and can be deposited in mountain streams and irrigation ponds through the actions of the wind and rain. To address such issues, the author previously examined the potential of natural materials, which are readily available in agricultural areas, for use as Cs adsorbents in mountain streams and reservoirs [7]. More specifically, the examination of five different natural materials indicated that carbonized rice hull and beech sawdust were the most promising adsorbents, and batch adsorption experiments revealed that the adsorption isotherms of these two natural materials fitted well with the Freundlich adsorption isotherm.

Thus, to determine the adsorption characteristics of carbonized rice hull and beech sawdust, the author reports the use of fixed-bed adsorption experiments based on the findings obtained in previous batch Cs adsorption experiments. The author will also attempt to estimate the length of the adsorption zone in the fixed-bed layer by the existing model equation to theoretically describe the curves obtained in these experiments.

\section{Materials and Methods}

\subsection{Materials}

Carbonized rice hull (commercially available) and beech 
sawdust (from the Yamagata prefecture) were selected as the natural materials of interest based on their previous identification as candidate materials for Cs adsorption [7]. The physical properties of these materials were reported in our previous study [7]. Minimal screening was carried out on the carbonized rice hull and beech sawdust samples to minimize the number of steps required during their potential utilization in the field. The $\mathrm{pH}$ values of the two materials in aqueous solution were measured using a 1:2.5 mass ratio of the natural material to distilled water [8]. Carbonized rice hull gave a solution $\mathrm{pH}$ of 7.25 , while beech sawdust gave a $\mathrm{pH}$ of 6.42. Prior to carrying out any further experiments, each material was pretreated using a previously described procedure [7].

\subsection{Fixed-bed Adsorption Experiments}

To obtain breakthrough curves for each natural adsorbent, fixed-bed adsorption experiments were performed using a glass column (height: $50 \mathrm{~cm}$, diameter: $\varphi 2 \mathrm{~cm}$ ) and a continuous flow system. A schematic representation of the apparatus is provided in Figure 1, and the experimental conditions employed are listed in Table 1 . The experiment was performed under variable packed-bed heights and at a constant Cs solution flow speed (i.e., $20 \mathrm{~mL} \mathrm{~min}^{-1}$ for

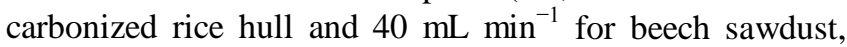
Table 1). The obtained breakthrough curves were then employed to determine the relationship between the packed-bed height and the Cs adsorption processes under a constant Cs solution flow speed.

Upon flowing the Cs solution through the column, the eluted solution was collected at the outlet at every 10 minutes in the first half of the experiment and at every 30 minutes in the latter half. The sample solutions were then filtered through membrane filters (pore size: $\varphi 0.45 \mu \mathrm{m}$, Whatman Inc., USA), and the Cs concentrations in the filtrates were determined using ion chromatography (IC-2010, Tosoh Corp., Japan). A standard Cs solution (Wako Pure Chemical Industries, Ltd., Japan) was used as the feed solution for the packed bed.

\subsection{Calculation of the Adsorption Zone in the Packed Bed Layer}

Breakthrough curves can either by studied by numerical analysis or using the approximate solutions method [9]. However, if specific measurements are available for a breakthrough curve, it is possible to analyze the result using a simple approximate expression or a somewhat stricter numerical solution [9]. In the case of this study, the results obtained from the breakthrough experiments are discussed in the context of the existing model equation (see Eq. (1) below) for the design of fixed-bed adsorption apparatus to ultimately determine the optimal length of the fixed-bed adsorption zone.

Michaels [10] proposed that a mass transfer zone known as the adsorption zone is formed by ion exchange in the fixed adsorption layer. This phenomenon assumes that the adsorbate (a single component) present in the fluid supplied to the fixed-bed at a constant concentration, constant temperature, and constant flow rate moves towards the exit through a specific length of mass transfer zone, which is formed after a certain process time.

When only one component is adsorbed, the mass balance equation within the adsorption zone can be defined as follows [11]:

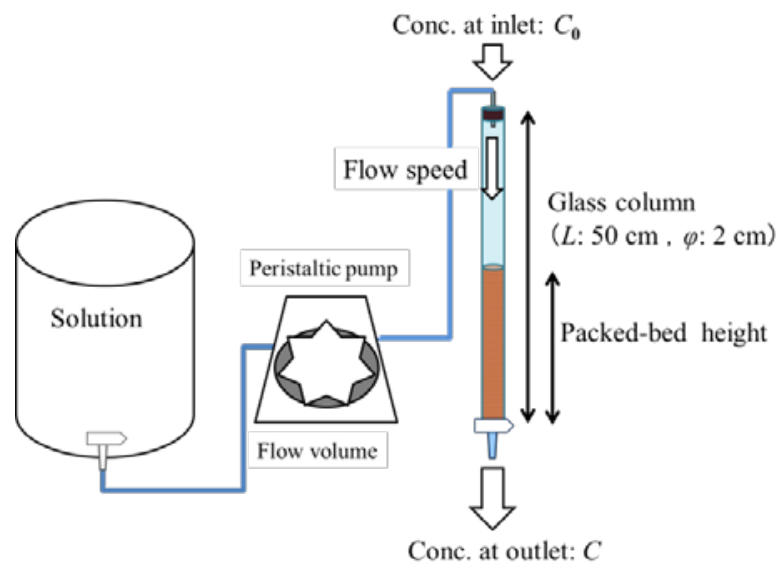

Figure 1. Schematic representation of the apparatus employed for the fixed-bed adsorption experiments.

Table 1. Conditions employed for the fixed-bed adsorption experiments

\begin{tabular}{|c|c|c|c|c|}
\hline \multirow{2}{*}{$\begin{array}{c}\text { Carbonized rice } \\
\text { hull }\end{array}$} & $\begin{array}{c}\text { Filled } \\
\text { adsorbent } \\
(\mathrm{g})\end{array}$ & $\begin{array}{c}\text { Height of fixed } \\
\text { adsorbent bed } \\
(\mathrm{cm})\end{array}$ & $\begin{array}{c}\text { Solution } \\
\text { flow speed } \\
\left(\mathrm{mL} \mathrm{min}^{-1}\right)\end{array}$ & $\begin{array}{c}\text { Initial Cs } \\
\text { concentration } \\
\left(\mathrm{mg} \mathrm{L}^{-1}\right)\end{array}$ \\
\cline { 2 - 3 } & 5 & 9 & \multirow{2}{*}{20} & \multirow{2}{*}{10} \\
\cline { 2 - 3 } & 10 & 13 & & \\
\hline
\end{tabular}

\begin{tabular}{|c|c|c|c|c|}
\hline \multirow{2}{*}{$\begin{array}{c}\text { Beech } \\
\text { sawdust }\end{array}$} & $\begin{array}{c}\text { Filled } \\
\text { adsorbent } \\
\text { (g) }\end{array}$ & $\begin{array}{c}\text { Height of } \\
\text { fixed } \\
\text { adsorbent bed } \\
\text { (cm) }\end{array}$ & $\begin{array}{c}\text { Solution } \\
\text { flow speed } \\
\left(\mathrm{mL} \mathrm{min}^{-1}\right)\end{array}$ & $\begin{array}{c}\text { Initial Cs } \\
\text { concentration } \\
\left(\mathrm{mg} \mathrm{L}^{-1}\right)\end{array}$ \\
\cline { 2 - 3 } & 10 & 15 & & \multirow{2}{*}{40} \\
\cline { 2 - 3 } & 20 & 26 & & 10 \\
\hline
\end{tabular}




$$
u(\partial c / \partial z)_{t}+\varepsilon_{b}(\partial c / \partial t)_{z}+\rho_{b}(\partial q / \partial t)_{z}=0
$$

where $u$ is the solution flow rate $\left(\mathrm{m} \mathrm{hr}^{-1}\right), c$ is the solution concentration $\left(\mathrm{kg} \mathrm{m}^{-3}\right), q$ is the degree of adsorption $(\mathrm{kg}$ $\left.\mathrm{kg}^{-1}\right), t$ is the elapsed time (h), $\mathrm{z}$ is the height of the packed layer $(\mathrm{m}), \rho_{b}$ is the apparent density of the packed layer $(\mathrm{kg}$ $\mathrm{m}^{-3}$ ), and $\varepsilon_{b}$ is the void ratio (-).

In this case, Eq. (2) can be substituted into Eq. (1) in place of $t$ to change the time reference from the column inlet to the column outlet. In this case, $\boldsymbol{\varepsilon}_{\boldsymbol{b}} z$ / $\boldsymbol{u}$ the time required to fill the voids between the particles with the incoming solution [12]:

$$
\theta=t-\varepsilon_{b} \mathrm{z} / u
$$

Therefore, Eq. (1) can be replaced by Eq. (3):

$$
u(\partial c / \partial z)_{\theta}+\rho_{b}(\partial q / \partial \theta)_{z}=0
$$

In addition, the rate of movement of the adsorption zone, $v_{a}$, can be represented by Eq. (4):

$$
v_{a}=(\partial z / \partial t)_{c}=-(\partial c / \partial t)_{z} /(\partial c / \partial z)_{t}
$$

Assuming that the shape of the adsorption zone remains constant and that movement takes place at a constant rate, $v_{a}$ is independent of the concentration $c$, and so $(\partial q / \partial c)_{z}$ must be constant:

$$
(\partial q / \partial c)_{z}=A_{1} \therefore q=A_{1} c+A_{2}
$$

where, $A_{1}, A_{2}$ are constant. This equation therefore satisfies the following boundary conditions:

$$
c=0 ; q=0 ; c=c_{0} ; q=q_{0}
$$

As such, Eq. (5) can be substituted to give Eq. (7):

$$
q=\left(q_{0} / c_{0}\right) c
$$

The rate of movement, $v_{a}$, of the adsorption zone can then be calculated through a combination of Eqs. (4) and (6) to give Eq. (8):

$$
v_{a}=u /\left(\varepsilon_{b}+\rho_{b}\left(q_{0} / c_{0}\right)\right) \cong u c_{0} / \rho_{b} q_{0}
$$

Where $\varepsilon_{b}<<\rho_{b} q_{0} / c_{0}$ The adsorption zone can therefore be defined according to Eq. (9) [11]:

$$
Z_{a}=v_{a}\left(t_{E}-t_{B}\right)=\left(u c_{0} / \rho_{b} q_{0}\right)\left(t_{E}-t_{B}\right)
$$

where $t_{\mathrm{B}}$ is the breakthrough points and $t_{\mathrm{E}}$ is the end points in the breakthrough curve.

In this case, as the values of $v_{a}, u, c_{0}, \rho_{b}$, and $q_{b}$ and the difference between $t_{E}$ and $t_{B}$ were obtained experimentally, the adsorption zone, $Z_{a}$ could be estimated by substituting the measured values directly into Eq. (9).

\section{Results and Discussion}

\subsection{Fixed-Bed Adsorption Experiments}

The results of the fixed-bed adsorption experiments (i.e., the breakthrough experiments) are shown in Figure 2, where the ratio of the Cs concentration at the column outlet $(C)$ to that at the inlet $\left(C_{0}\right)$, i.e., $C / C_{0}$, is plotted against the time elapsed since commencing the solution flow through the column at the desired rate. The origin of the $\mathrm{x}$-axis (i.e., the elapsed time) is set at $C / C_{0}=0.5$, and the negative values indicate the time elapsed prior to this point. Figure 2 also indicates the value of $C / C_{0}$ (in addition to $C_{\mathrm{B}}$ and $C_{\mathrm{E}}$ ) at the breakthrough points $\left(t_{\mathrm{B}}\right)$ and end points $\left(t_{\mathrm{E}}\right)$ of the breakthrough curves. In this case, $C_{\mathrm{B}}$ is defined as the Cs concentration at the column outlet when $C / C_{0}=0.05$, while $C_{\mathrm{E}}$ is the Cs concentration when $C / C_{0}=0.95$. However, in the case of the carbonized rice hull, $C_{\mathrm{E}}$ is the Cs concentration at the end of the experiment.

As shown in Figure 2, the various trajectories of the breakthrough curves obtained under a range of conditions were similar for each natural material but differed significantly between the two materials. In the case of carbonized rice hull, an increase in Cs concentration in the column outlet solution was observed for all packed-bed heights examined (Figure 2(a)). In addition, for a packed-bed height of $17 \mathrm{~cm}$, the breakthrough point, $t_{\mathrm{B}}$, was reached within $0.1 \mathrm{~h}$, while for bed heights of 9 and $13 \mathrm{~cm}$, negative values of $t_{\mathrm{B}}$ were observed (see Table 2). Moreover, the increase in $C / C_{0}$ values of the breakthrough curves began to slow beyond $C / C_{0}=0.5$ (Figure 2(a)), and the end point, $t_{\mathrm{E}}$, was reached between 4.9 and $7.7 \mathrm{~h}$.

In contrast, the breakthrough curves of beech sawdust were typically sigmoidal (Figure 2(b)), and the slope of the curve increased gradually upon commencing the experiment. In addition, the Cs concentration at the column outlet in the final stage was approximately 1.1-1.2 times that of the inlet concentration at equilibrium, i.e., $C / C_{0}$ was greater than unity. Furthermore, the breakthrough point, $t_{\mathrm{B}}$, was reached between 0.2 and $0.5 \mathrm{~h}$. The trends obtained from these results were similar to the results of experiments that were conducted with the same bed layer height and various Cs flow speeds [12].

These results thereby indicate that the breakthrough curves of carbonized rice hull were asymmetrical at the origin, indicating that the breakthrough point appeared relatively early, while a long adsorption time was required to reach the end point. In contrast, the breakthrough curves of beech sawdust indicated that the Cs concentration at the outlet $(C)$ exceeded that at the inlet $\left(C_{0}\right)$ prior to reaching the equilibrium state. 
Table 2. Times at the breakthrough points and end points of the experiments

\begin{tabular}{|c|c|c|c|c|c|c|}
\hline \multirow[b]{2}{*}{ Packed bed layer height $(\mathrm{cm})$} & \multicolumn{3}{|c|}{ Carbonized rice hull } & \multicolumn{3}{|c|}{ Beech sawdust } \\
\hline & 9 & 13 & 17 & 15 & 20 & 26 \\
\hline$t_{\mathrm{B}}$ : Elapsed time at breakthrough point (h) & $-1.0 \times 10^{2}$ & $-2.0 \times 10^{2}$ & 0.1 & 0.2 & 0.3 & 0.6 \\
\hline$t_{\mathrm{E}}:$ Elapsed time at end point (h) & $4.9 *$ & $6.5^{*}$ & $7.7^{*}$ & 1.2 & 0.9 & 1.7 \\
\hline$t_{\mathrm{E}-\mathrm{B}}:$ Elapsed time between $C_{\mathrm{B}}$ and $C_{\mathrm{E}}(\mathrm{h})$ & 4.9 & 6.5 & 7.6 & 1.0 & 0.6 & 1.1 \\
\hline
\end{tabular}

* Indicates the time at the end of the experiment for carbonized rice hull
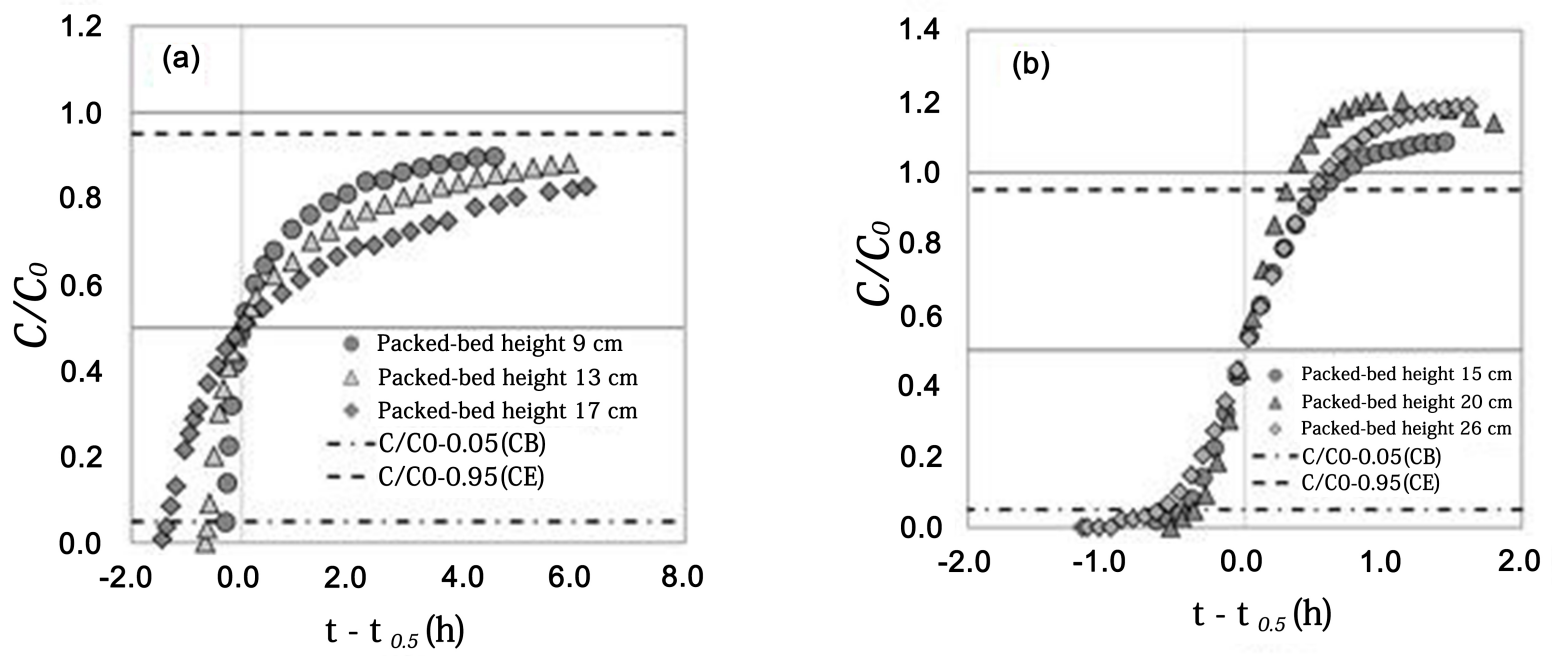

Figure 2. Breakthrough curves for (a) carbonized rice hull with a Cs solution flow speed of $20 \mathrm{~mL} \mathrm{~min}^{-1}$ and (b) beech sawdust with a Cs solution flow speed of $40 \mathrm{~mL} \mathrm{~min}^{-1}$ with variable packed-bed heights.

Table 3. Cs mass balances in the packed-bed layers and Cs adsorption ratios during the experiments

\begin{tabular}{|c|c|c|c|c|c|c|}
\hline & \multicolumn{3}{|c|}{ Carbonized rice hull } & \multicolumn{3}{|c|}{ Beech sawdust } \\
\hline Packed bed layer height (cm) & 9 & 13 & 17 & 15 & 20 & 26 \\
\hline Total inflow of Cs (mg) & 58.4 & 78.5 & 90.7 & 23.8 & 16.0 & 26.8 \\
\hline Total outflow of Cs (mg) & 44.2 & 56.8 & 58.9 & 12.6 & 7.5 & 12.4 \\
\hline Total adsorbed Cs in column (mg) & 14.2 & 21.6 & 31.8 & 11.2 & 8.5 & 14.4 \\
\hline Adsorbed Cs per unit weight of material (mg) & 2.8 & 2.7 & 3.2 & 1.1 & 0.6 & 0.7 \\
\hline Cs adsorption ratio in column (\%) & 24.4 & 27.6 & 35.1 & 47.2 & 53.2 & 53.6 \\
\hline
\end{tabular}

\subsection{Mass Balance in the Packed-Bed Layer}

Based on the results of the fixed-bed adsorption experiments, the Cs mass balance and Cs adsorption ratio inside the packed-bed layers were determined as shown in Table 3. From these results, it was apparent that the quantity of Cs adsorbed per unit weight of adsorbent was greater for carbonized rice hull than for beech sawdust (Table 3). It should be noted here that the $\mathrm{pH}$ of the adsorption solution can have a significant influence on the adsorption process itself [13]. For example, the binding of metal ions by surface functional groups has been reported to be $\mathrm{pH}$ dependent [14]. In this case, the $\mathrm{pH}$ of the carbonized rice hull solution (i.e., $\mathrm{pH}$ 7.25) was higher than that of the beech sawdust solution (i.e., $\mathrm{pH}$ 6.42), which may partly account for the variation in adsorption quantities between these two materials. However, with a constant solution flow speed no significant trend was observed in the relationship between the Cs adsorption per unit weight and the packed-bed height for either material (Table 3).

The author also found that the adsorption rate was higher for the carbonized rice hull packed-bed (i.e., 24.4-35.1\%) than for the beech sawdust bed (i.e., 47.2-53.6\%). This result for beech sawdust is similar to that obtained in our previous adsorption experiments using the batch method [7], where an adsorption rate of $45 \%$ was obtained. However, the adsorption ratio for carbonized rice hull obtained using the batch method was $\sim 90 \%$, which is significantly greater than that obtained in this study. In addition, the combination of our previously estimated adsorption rate [7] with the shape of the carbonized rice hull breakthrough curve obtained herein suggests that the adsorption rate of the carbonized rice hull is extremely slow. In this column-based adsorption experiment, Cs flows from the outlet after a single contact with the adsorbent. However, the author considered that the adsorption ratio become higher than that of the column method since the batch method repeated 
contact between Cs and the natural adsorbent.

Based on the above assumptions, in the case of carbonized rice hull, it was expected that a reduction in the solution flow rate through the column would prolong the contact time between the solution and the adsorbent, thereby increasing the quantity of Cs adsorbed. As such, it could be proposed that the selection of a sufficiently low flow rate would allow a comparable adsorption rate to be obtained for the column system to that obtained in the batch experiments.

\subsection{Estimation the Length of the Adsorption Zone}

The author then attempted to theoretically explain the breakthrough curves obtained in the fixed adsorption layer experiments using carbonized rice hull and beech sawdust through the commonly used model for the design of fixed-bed adsorption apparatus [10-11].

Thus, using the data obtained from the fixed-bed adsorption experiments carried out under a range of conditions, the length of the adsorption zone formed in the fixed-bed, $Z_{a}$, was estimated. During continuous feeding of the solution into the column, the adsorption zone moves downwards at a significantly slower speed than the solution flow speed [11]. When the lower end of the adsorption zone reaches the lower part of the fixed-bed layer, the adsorbate present in the solution appears at the outlet, and the concentration $C$ reaches $C_{0}$. Thus, the parameters and calculated values applied to Eq. (9) to determine the lengths of the adsorption zones for the various bed heights are shown in Table 4. In the case of carbonized rice hull, the adsorption zone $Z_{a}$ was $29.1 \mathrm{~cm}$ with a packed bed height of $9 \mathrm{~cm}, 33.1 \mathrm{~cm}$ with a packed bed height of $13 \mathrm{~cm}$, and 39.8 $\mathrm{cm}$ for a packed bed height of $17 \mathrm{~cm}$. In contrast, in the case of beech sawdust, $Z_{a}$ was $77.5 \mathrm{~cm}$ with a packed bed height of $15 \mathrm{~cm}, 77.0 \mathrm{~cm}$ for a packed bed height of $20 \mathrm{~cm}$, and $74.0 \mathrm{~cm}$ for a packed bed height of $26 \mathrm{~cm}$. These results indicate that for carbonized rice hull, the length of the adsorption zone increased with increasing packed-bed height, with the opposite being true for beech sawdust. In addition, these results imply that the adsorption zone is beyond the height of the packed layer and protrudes out of the column. However, these measured values are clearly not realistic.

It can therefore be considered that this model equation satisfies the assumption that the adsorption zone does not change its shape and that it moves at a constant speed, $v_{a}$. However, the obtained results imply that this assumption does not hold true in the fixed-bed adsorption experiments carried out herein. Furthermore, in the case of beech sawdust, it is also considered that these calculated results are attributable to the fact that the column outlet concentration becomes larger than the inlet concentration (i.e., $C>C_{0}$ ) prior to reaching the equilibrium state. This phenomenon for the beech sawdust, that is, is different from the general breakthrough curve that indicated the outlet concentration becomes equal to the inlet concentration as the equilibrium state is approached.

It is therefore apparent from the above results that to theoretically explain the breakthrough curves obtained using carbonized rice hull and beech sawdust, the construction of a novel model formula is required since the provided model is not suitable to describe the adsorption in these experiments. Additional experiments will be required examine the effect of the solution flow rate and the Cs concentration to discuss why there results for both materials were differences. These experiments are currently being considered and will be carried out in due course.

Table 4. Parameters and values for estimation of the adsorption zone lengths for the various experiments

\begin{tabular}{|c|c|c|c|c|c|c|c|c|c|c|}
\hline \multirow{2}{*}{ Material } & $\begin{array}{l}\text { Packed-bed } \\
\text { layer height }\end{array}$ & $Z_{a}$ & $u$ & $c_{0}$ & $q_{0}$ & $\rho_{b}$ & $v_{a}$ & $t_{\mathrm{B}}$ & $t_{\mathrm{E}}$ & $T_{\mathrm{E}-\mathrm{B}}$ \\
\hline & (cm) & $(\mathrm{cm})$ & $\left(\mathrm{m} \mathrm{h}^{-1}\right)$ & $\left(\mathrm{kg} \mathrm{m}^{-3}\right)$ & $\left(\mathrm{kg} \mathrm{kg}^{-1}\right)$ & $\left(\mathrm{kg} \mathrm{m}^{-3}\right)$ & $\left(\mathrm{m} \mathrm{h}^{-1}\right)$ & (h) & (h) & (h) \\
\hline \multirow{3}{*}{$\begin{array}{l}\text { Carbonized } \\
\text { rice hull }\end{array}$} & 9 & 29.1 & 3.8 & $1.0 \times 10^{-2}$ & $3.0 \times 10^{-3}$ & 187.2 & $5.9 \times 10^{-2}$ & $-1.0 \times 10^{2}$ & 4.9 & 4.9 \\
\hline & 13 & 33.1 & 3.8 & $1.0 \times 10^{-2}$ & $4.0 \times 10^{-3}$ & 195.9 & $5.1 \times 10^{-2}$ & $-2.0 \times 10^{2}$ & 6.5 & 6.5 \\
\hline & 17 & 39.8 & 3.8 & $1.0 \times 10^{-2}$ & $4.0 \times 10^{-3}$ & 192.9 & $5.2 \times 10^{-2}$ & 0.1 & 7.7 & 7.6 \\
\hline \multirow{3}{*}{$\begin{array}{c}\text { Beech } \\
\text { sawdust }\end{array}$} & 15 & 77.5 & 7.6 & $1.0 \times 10^{-2}$ & $4.7 \times 10^{-4}$ & 212.2 & $7.8 \times 10^{-1}$ & 0.2 & 1.2 & 1 \\
\hline & 20 & 77.0 & 7.6 & $1.0 \times 10^{-2}$ & $2.5 \times 10^{-4}$ & 238.7 & 1.3 & 0.3 & 0.9 & 0.6 \\
\hline & 26 & 74.0 & 7.6 & $1.0 \times 10^{-2}$ & $4.6 \times 10^{-4}$ & 244.9 & $6.7 \times 10^{-1}$ & 0.6 & 1.7 & 1.1 \\
\hline
\end{tabular}




\section{Conclusions}

Fixed-bed layer adsorption experiments were conducted to investigate the adsorption breakthrough curves of carbonized rice hull and beech sawdust as natural adsorbents for the removal of Cs from solution. Based on the results of the experiments performed using a continuous flow system and a variable packed-bed height of these natural materials, a number of conclusions could be drawn. Firstly, the breakthrough curves of carbonized rice hull were asymmetrical at the origin, indicating that the breakthrough point appeared relatively early, while a long adsorption time was required to reach the end point. In contrast, the breakthrough curves of beech sawdust indicated that the Cs concentration at the outlet exceeded that of the inlet prior to equilibrium. In addition, the mass balance of the packed-bed layer was estimated, and it was found that the quantity of Cs adsorbed per unit weight of adsorbent is greater for carbonized rice hull than for beech sawdust. Furthermore, the adsorption ratio in the packed-bed was higher for beech sawdust than for carbonized rice hull. However, following estimation of the length of the adsorption zone formed in the packed bed using the model formula commonly employed in the design of fixed-bed adsorption apparatus, it is not possible to calculate the real length of the adsorption zone. The author could therefore conclude that to generalize the Cs adsorption phenomena of natural materials such as those examined herein for application in the adsorption of radioactive $\mathrm{Cs}$ from environmental water sources, additional fixed-bed adsorption experiments to examine the effect of the solution flow rate and the Cs concentration in solution are required.

\section{Acknowledgements}

This work was supported by JSPS KAKENHI Grant Number 2651108.

\section{REFERENCES}

[1] J. Shibata, S. Furuyanaka, N. Murayama and S Iyogi, Development of processing technology for aqueous liquor containing high level radioactive elements discharged from Fukushima nuclear power plant, Special emergency collaborative research, 23U-11, Kyoto Univ. Disaster Prevention Research Institute, PP.21, 2012.

[2] Y. Okamura, K. Fujiwara, N. Iijima, T. Syoda, K. Suzuki, T.
Sugo, T. Shimizdu, R. Itagaki, A. Takahashi, T. Ono, T. Kikuchi, T. Someya, R. Ishihara, T. Kojima, D. Umeno and K. Saito, Preparation of adsorptive fibers for removal of cesium from seawater. Journal of Ion Exchange, 24(1), 8-12, 2013 (in Japanese).

[3] K. Sato, S. Takiuchi, M. Kakuta, R. Suzuki, H. Sakai and N. Sakamoto, Removal and adsorption of radioactive cesium from contaminated soil caused by the Fukushima Daiichi nuclear power station accident. Bunseki Kagaku, 62(6), 535540, 2013 (in Japanese).

[4] K. Ito, H. Miyahara, T. Ujiie, T. Takeshima, S. Yokohama, K. Nakata, T. Nagano, T. Sato, T. Hatta, and H. Yamada, Practical approach to decontamination of radioactive cesium-contaminated matter in agricultural region by improved wet classification and use of geometrical. Atomic Energy Society Japan, 11(4): 255-271, 2012 (in Japanese).

[5] K. Sasaki, H. Morikawa, T. Kishibe, A. Mikami, T. Harada and M. Ohta, Practical removal of radioactivity from sediment mud in a swimming pool in Fukushima, Japan by immobilized photosynthetic bacteria, Bioscience, Biotechnology, and Biochemical,76(4), 859-852, 2012.

[6] K. Sasaki, Morikawa H., Kishibe T., Mikami A., Takeo K., Harada T. and Ohta M., Practical removal of radioactivity from soil in Fukushima using immobilized photosynthetic bacteria combined with anaerobic digestion and lactic acid fermentation as pre-treatment. Bioscience, Biotechnology, and Biochemical, 76(9), 1809-1814, 2012.

[7] A. Miura, T. Kubota, K. Hamada, and T. Hitomi, Adsorption efficiency of natural materials for low-concentration cesium in solution. Water Science and Technology, 73 (10), 24532460, 2016.

[8] M. Nakano, T. Miyazaki, S. Shiozawa, and T. Nishimura, Physical and environmental analysis of soils, University of Tokyo Press, 1995.

[9] Y. Takeuchi, Wakariyasui kyuchaku no sokutei to kaiseki (Measurement and analysis of easy-to-understand adsorption). Bunrigijyutu kai, Japan, PP.170, 2011 (in Japanese).

[10] A.S. Michaels, Simplified method of interpreting kinetic data in fixed-bed ion exchange. Industrial Engineering Chemistry Research, 44(8), 1922-1930, 1952.

[11] K. Hashimoto, Design of fixed layer adsorption apparatus. Mizusyorigijyutu, 13(2), 37-47, 1972 (in Japanese).

[12] A. Miura, Mechanism of cesium adsorption by carbonized rice hull and beech sawdust [proceedings], The 18th International Conference on Diffuse Pollution and Eutrophication, Los Angeles, USA, August 13-17, 2017.

[13] C. J. H. Wevers, Research on ion exchangers by means of the percolation technique, Chemical Engineering Science, 10, 171-189, 1959.

[14] M. Madhava Rao, A. Ramesh, G. Purna Chandra Rao and K. Seshaiah, Removal of copper and cadmium from the aqueous solutions by activated carbon derived from Ceiba pentandra hulls. Journal of Hazardous Materials, B129, 123-129, 2016. 